\title{
Pembuatan Lapisan Tipis Oksida Grafena Tereduksi sebagai Material Elektroda Sistem Kapasitor dan Karakterisasinya
}

\author{
Vika Marcelina, ${ }^{1}$ Fitri Yuliasari, ${ }^{1}$ Yeni W Hartati, ${ }^{2}$ Fitrilawati, ${ }^{1, *}$ dan Norman Syakir ${ }^{1, \dagger}$ \\ ${ }^{1}$ Departemen Fisika, Universitas Padjadjaran, Jalan Raya Bandung-Sumedang KM 21, Jatinangor, Sumedang, 45363 \\ ${ }^{2}$ Departemen Kimia, Universitas Padjadjaran, Jalan Raya Bandung-Sumedang KM 21, Jatinangor, Sumedang 45363
}

Intisari

Grafena adalah material karbon dua dimensi dan memiliki sifat mekanik, listrik, dan termal yang unggul. Grafena memiliki potensi sebagai bahan elektroda sistem penyimpanan energy seperti superkapasitor. Dalam penelitian digunakan bahan reduced graphene oxide (RGO) yang diperoleh melalui proses reduksi secara termal bahan graphene oxide (GO) komersial. Lapisan tipis GO di atas substrat ITO-glass dibuat menggunakan metode spin-coating pada kecepatan 1000 rpm selama 60 sekon. Lapisan tipis RGO diperoleh dengan cara pemanasan lapisan tipis $\mathrm{GO}$ pada temperatur $200^{\circ} \mathrm{C}$ selama $1 \mathrm{jam}$. Sistem kapasitor menggunakan anoda dan katoda dari bahan RGO di atas dan untuk medium elektrolit digunakan larutan $\mathrm{H}_{2} \mathrm{SO}_{4} 1$ Molar. Karakteristik sistem kapasitor tersebut diamati melalui pengukuran cyclic voltammetry $(\mathrm{CV})$ secara potensio-static pada rentang tegangan -0,2-0,8 volt dengan scan rate $125 \mathrm{mV} / \mathrm{s}$. Juga dilakukan karakteristik charge-discharge melalui pengukuran pengisian-pengosongan muatan secara galvano-static. Karakteristik sifat penyimpanan muatan secara kapasitip diperlihatkan dengan adanya pola histerisis pada hasil kurva CV. Hasil pengukuran charge-discharge memperlihatkan pola kurva segitiga yang mengindikasikan adanya proses penyimpanan muatan. Nilai kapasitansi spesifik maksimum elektroda RGO adalah $1,54 \times 10^{-4} /$ massa $\mathrm{F} / \mathrm{g}$ pada kondisi arus pengosongan 0,7 $\mu \mathrm{A}$.

\begin{abstract}
Graphene is a two-dimensional carbon material and has superior mechanical, electrical, and thermal properties. Graphene has potential as an electrode material for energy storage systems such as supercapacitors. In the study used reduced graphene oxide (RGO) material obtained through the thermal reduction process of commercial graphene oxide (GO) material. The GO thin layer on the ITO-glass substrate was made using Spin coating method at $1000 \mathrm{rpm}$ for 60 seconds. The RGO thin layer was obtained by heating the GO thin film at a temperature of $200^{\circ} \mathrm{C}$ for 1 hour. The capacitor system uses the anode and cathode of the above RGO material and for the electrolyte medium, a 1 Molar $\mathrm{H}_{2} \mathrm{SO}_{4}$ solution is used. The characteristic of the capacitor system was observed by potential-static cyclic voltammetry $(\mathrm{CV})$ measurements in the voltage range of -0.2-0.8 volts with a scan rate of $125 \mathrm{mV} / \mathrm{s}$. Also performed the characteristics of charge-discharge through the measurement of charge-discharging charge in galvanostatic. Characteristic properties of energy storage are shown in the presence of a pattern of hysteresis on the CV curve. The result of the charge-discharge measurement shows a triangle curve pattern indicating the existence of a storage process of the charge. The maximum specific capacitance value of RGO electrode is $1.54 \times 10^{-4} /$ mass $\mathrm{F} / \mathrm{g}$ at $0.7 \mu \mathrm{A}$ discharge current condition.
\end{abstract}

KATA KUNCI: graphene oxide, reduced graphene oxide, capasitor,thermal reduction, charge-discharge http://dx.doi.org/10.12962/j24604682.v13i3.2841

\section{PENDAHULUAN}

Salah satu jenis kapasitor adalah superkapasitor. Superkapasitor memiliki kelebihan yakni proses penyimpanan muatan yang cepat [1], memiliki ketahanan siklus yang lama ( $>100.000$ siklus) [2], cepat dalam pengisian dan pengosongan muatan pada rapat daya di atas $1 \mathrm{~kW} / \mathrm{kg}[1]$, memiliki kapasitas daya yang tinggi [2], dan pemeliharaannya yang

\footnotetext{
*E-MAIL: fitrilawati@phys.unpad.ac.id
}

†E-MAIL: n.sjakirephys. unpad.ac.id mudah [1]. Material karbon berpori biasanya dipilih sebagai elektroda [3] karena konduktivitas listriknya yang tinggi [4], memiliki permukaan yang luas (diatas $2500 \mathrm{~m}^{2} / \mathrm{g}$ ), murah, dan mudah didapat [5]. Grafena sebagai salah satu alotrop karbon yang ditemukan pada tahun 2004 [6] merupakan material karbon 2D yang memiliki tebal satu atom karbon [7] dengan luas permukaan spesifik $2630 \mathrm{~m}^{2} \mathrm{~g}^{-1}$ [8] memiliki sifat mekanik, termal, listrik dan optik yang luar biasa [9]. Grafit menjadi oksida grafit merupakan precursor graphene oxide (GO) [10]. Keuntungan utama dari GO adalah harganya yang murah dan tersedia dalam jumlah banyak. GO merupakan material yang banyak digunakan berkaitan dengan material grafena namun memiliki sifat yang kurang baik, 
seperti luas permukaan spesifik yang rendah, memiliki kerapatan gugus oksigen yang tinggi, dan bersifat isolator [11]. Sehingga untuk mengaplikasikan GO sebagai material elektroda superkapasitor perlu dilakukan proses reduksi menjadi reduced graphene oxide (RGO) melalui reduksi secara termal untuk mendekati konduktivitas listrik seperti grafena yakni $400 \Omega / \mathrm{cm}$ pada temperatur ruang [6].

Bahan RGO dapat pula dipadukan dengan ITO-glass sebagai elektroda superkapasitor untuk meningkatkan nilai kapasitansis pesifiknya. Namun masih memiliki kekurangan yakni, superkapasitor masih memiliki nilai rapat energy spesifik yang lebih rendah dibandingkan baterai [2]. Oleh sebab itu, perlu dilakukan kajian untuk mengetahui bagaimana karakteristik film tipis RGO pada substrat ITO-glass sebagai material elektroda system kapasitor. Sehingga selanjutnya akan diketahui potensi RGO untuk diaplikasikan sebagai material elektroda superkapasitor. Pengukuran pengisian-pengosongan secara galvanostatik dilakukan dengan $1 \mathrm{M} \mathrm{H}_{2} \mathrm{SO}_{4}$ sebagai medium elektrolit pada variasi arus $0,5 \mu \mathrm{A}, 0,6 \mu \mathrm{A}$, dan 0,7 $\mu \mathrm{A}$.

\section{METODE PENELITIAN}

Dalam penelitian ini film tipis RGO dibuat dari GO komersil $4 \mathrm{mg} / \mathrm{ml}$ (Graphenea SA ES A75022608) yang diencerkan menggunakan mili- $Q$ water menjadi konsentrasi $1 \mathrm{mg} / \mathrm{ml} \mathrm{den-}$ gan menggunakan metode spin-coating. Proses reduksi secara termal dilakukan pada temperatur $200^{\circ} \mathrm{C}$ selama 1 jam. Dalam pembuatan film tipis RGO, substrat konduktif yang digunakan adalah substrat ITO-glass. Substrat ini dicuci dengan menggunakan teepol, lalu disonikasi dalam ultrasonic bath selama 15 menit pada temperatur $50^{\circ} \mathrm{C}$ dengan aquades dan ethanol secara bergantian. Pengeringan permukaan menggunakan air compressor.

GO komersil $4 \mathrm{mg} / \mathrm{ml}$ yang diencerkan dengan perbandingan sebesar 1: 4 antara GO dan mili-Q water untuk menghasilkan GO $1 \mathrm{mg} / \mathrm{ml}$. Selanjutnya larutan GO ini disonikasi selama 1 jam pada temperatur ruang. Kemudian dilakukan proses pembuatan film tipis di atas substrat ITO-glass menggunakan metode spin-coating dengan kecepatan $1000 \mathrm{rpm}$ selama 60 sekon. Film tipis yang terbentuk di atas substrat tersebut diannealing selama 1-2 menit di atas hotplate dengan temperatur $30^{\circ} \mathrm{C}$ untuk menghilangkan sisa pelarutnya.

Untuk membentuk film tipis RGO, film tipis GO direduksi gugus oksigennya dengan reduksi secara termal. Dimana film tipis GO dipanaskan di atas hotplate selama 1 jam pada temperatur $200^{\circ} \mathrm{C}$.

Karakterisasi film RGO yang dihasilkan dilakukan melalui pengukuran cyclic voltammetry $(\mathrm{CV})$ dan pengisianpengosongan secara galvanostatik. Dimana sel yang digunakan untuk pengukuran $\mathrm{CV}$ menggunakan sel elektrokimia system tiga elektroda dengan substrat ITO-glass yang dilapisi RGO sebagai elektroda kerja, platina sebagai elektroda bantu dan $\mathrm{Ag} / \mathrm{AgCl}$ sebagai elektroda referensi dengan $1 \mathrm{M} \mathrm{H}_{2} \mathrm{SO}_{4}$ sebagai medium elektrolit. Pengukuran dilakukan pada rentang tegangan $-0,2-0,8$ volt dengan scan rate $125 \mathrm{mV} / \mathrm{s}$. Untuk pengukuran pengisian-pengosongan

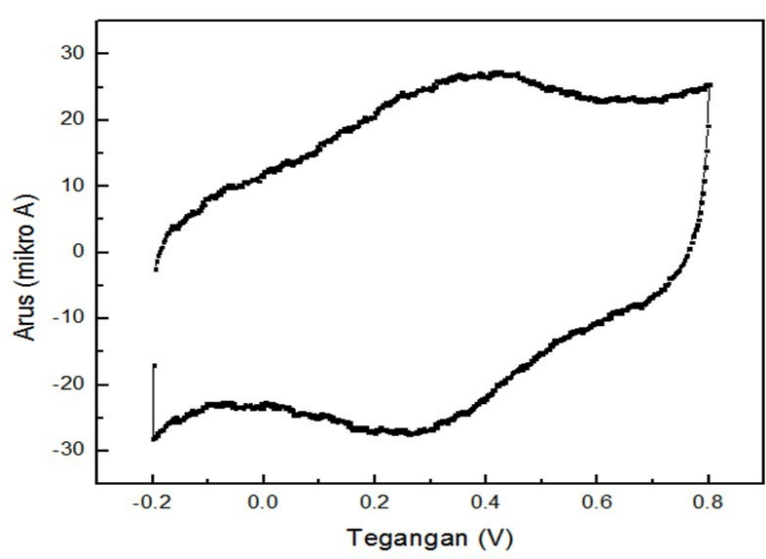

Gambar 1: Kurva CV RGO $1 \mathrm{mg} / \mathrm{ml}$ pada tegangan -0,2-0,8 V dan scan rate $125 \mathrm{mV} / \mathrm{s}$.

secara galvanostatik, menggunakan sel elektrokimia dengan sistem 2 elektroda dengan substrat ITO-glass yang dilapisi RGO sebagai elektrodakerja, platina sebagai elektroda bantu dengan $1 \mathrm{M} \mathrm{H}_{2} \mathrm{SO}_{4}$ sebagai medium elektrolit. Pengukuran ini dilakukan pada rentang tegangan $-0,2-0,8$ Volt dengan arus pengisian maupun pengosongan sebesar $0,5 \mu \mathrm{A}, 0,6 \mu \mathrm{A}$, dan $0,7 \mu \mathrm{A}$.

\section{HASIL DAN PEMBAHASAN}

Untuk mengetahui sifat kapasitif dari film RGO yang dibuat, maka dilakukan karakterisasi karakteristik cyclic voltammetry $(\mathrm{CV})$. Kurva $\mathrm{CV}$ yang dihasilkan dapat dilihat pada Gambar 1. Pola kurva dalam Gambar 1 terlihat membentuk hysteresis dengan bentuk kuasi-persegi. Hal tersebut menunjukkan bahwa elektroda yang digunakan memiliki sifat kapasitif [12], dimana ketika tegangan setelah mencapai $0,8 \mathrm{~V}$ dan diturunkan ketegangan $-0,2 \mathrm{~V}$, nilai arus yang dihasilkan tidak memiliki nilai yang sama seperti sebelumnya. Adanya puncak dan lembah pada kurva juga menunjukkan adanya proses reduksi-oksidasi pada elektroda RGO.

Gambar 2 memperlihatkan kurva pengisian-pengosongan secara galvano static elektroda RGO pada arus 0,5-0,7 $\mu \mathrm{A}$. Dari kurva tersebut, dapat terlihat hubungan antara tegangan dengan waktu yang memperlihatkan kurva berbentuk segitiga. Jenis kurva ini merupakan jenis superkapasitor berbasis karbon [12] dan data menunjukkan performa kapasitif yang cukup baik.

Dalam proses pengisian maupun pengosongan, waktu yang dibutuhkan akan semakin cepat jika arus pengisian atau pengosongannya semakin besar. Dimana arus berkaitan dengan banyaknya muatan yang disimpan oleh elektroda. Berdasarkan kurva tersebut, dapat dihitung nilai kapasitansi spesifik elektroda melalui Pers.(1):

$$
C=i \frac{\Delta t}{m \Delta V}
$$

dengan $\mathrm{C}$ adalah kapasitansi pesifik elektroda $\mathrm{RGO}$, i adalah arus pengosongan (A), $\Delta \mathrm{t}$ adalah waktu pengosongan (s), 


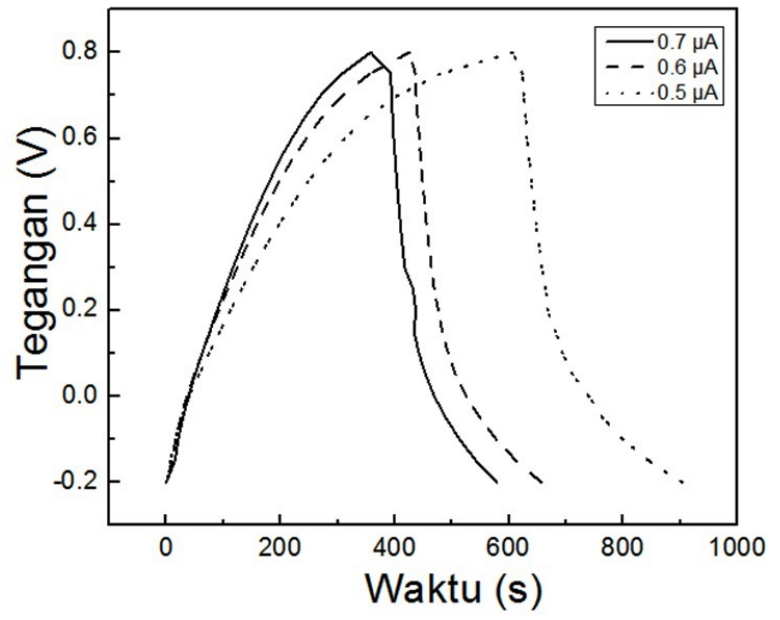

Gambar 2: Kurva pengisian-pengosongan elektroda RGO pada Arus $0,5-0,7 \mu \mathrm{A}$

$\Delta \mathrm{V}$ adalah lebar tegangan $(\mathrm{V})$, dan $\mathrm{m}$ adalah massa material aktif elektroda (gr). Sehingga dari pengukuran pengisianpengosongan diperoleh nilai kapasitansi spesifik maksimum dari elektroda RGO yang telah dibuat dengan konsentrasi $1 \mathrm{mg} / \mathrm{ml}$ sebesar $1,54 \times 10^{-4} / \mathrm{massa} \mathrm{F} / \mathrm{g}$ pada arus pengosongan $0,7 \mu \mathrm{A}$.

\section{SIMPULAN}

Lapisan tipis RGO yang dibuat dengan teknik spin-coating RGO berpotensi digunakan sebagai material elektroda kapasitor ataupun superkapasitor. Hal tersebut ditunjukan oleh kurva CV dan pengisian-pengosongan. Sifat kapasitif elektroda ditunjukkan oleh adanya hysteresis pada kurva CV dan kurva berbentuk segitiga pada pengukuran pengisianpengosongan. Nilai kapasitansi spesifik maksimum yang dicapai oleh elektroda RGO $1 \mathrm{mg} / \mathrm{ml}$ melalui pengukuran pengisian-pengosongan sekitar 1,54 $\times 10^{-4} /$ massa F/g pada arus pengosongan $0,7 \mu \mathrm{A}$. Namun masih diperlukan optimasi nilai massa film tipis RGO agar nilai kapasitan sijenis yang dihasilkan dapat diketahui secara pasti dari film tipis RGO yang dibuat.

\section{Ucapan Terima Kasih}

Penelitian ini didanai oleh proyek Penelitian Unggulan Perguruan Tinggi 2017 kontrak no. 718/UN6.3.1/PL/2017 tanggal 17 April 2017.
[1] A.K. Shukla, Resonance, 6(7), 72-81 (2001).

[2] A.G. Pandolfo and A.F. Hollenkamp, J. Power Sources, 157(1), 11-27 (2006).

[3] X.S. Zhao, L.L. Zhang, R. Zhou, and X.S. Zhao, J. Mater. Chem., 20, 5983-5992 (2010)

[4] E. Frackowiak, Carbon N. Y., 39, 937-950 (2001).

[5] R. Ko and M. Carlen, Electrochim. Acta, 45, 2483-2498 (2000).

[6] K. S. Novoselov, A. K. Geim, S. V Morozov, and D. Jiang, Science, 306, 666-669 (2004).
[7] J. Yang and S. Gunasekaran, Carbon N. Y., 51, 36-44 (2012).

[8] M.D. Stoller, S. Park, Y. Zhu, J. An, and R.S. Ruoff, Am. Chem. Soc., 8(10), 3498-3502 (2008).

[9] S. Pei and H. Cheng, Carbon N. Y., 11, 1-19 (2011).

[10] S. Park and R.S. Ruoff, Nat. Nanotechnol, 4, 217-224 (2009).

[11] H. Choi, S. Jung, J. Seo, and D. Wook, Nano Energy, 1(4), 534 551 (2012).

[12] R. Farma, et al., Int. J. Electrochem. Sci., 8, 257-273 (2013). 